\title{
SOLID SOLUTION HARDENING IN Mg-Gd-TM (TM=Ag, Zn and Zr) ALLOYS: AN INTEGRATED DENSITY FUNCTIONAL THEORY AND ELECTRON WORK FUNCTION STUDY
}

\author{
William Yi Wang, ${ }^{1,4,}{ }^{*}$ Shun Li Shang, ${ }^{1}$ Yi Wang, ${ }^{1}$ Hongyeun Kim, ${ }^{1}$ Kristopher A. Darling, ${ }^{2}$ Laszlo J. Kecskes, ${ }^{2}$ Suveen N. Mathaudhu, ${ }^{3}$ \\ $\mathrm{Xi}$ Dong Hui, ${ }^{4}$ and $\mathrm{Zi}-\mathrm{Kui}$ Liu ${ }^{1}$ \\ ${ }^{1}$ Department of Materials Science and Engineering, The Pennsylvania State University, University Park, PA 16802, USA \\ ${ }^{2}$ U.S. Army Research Laboratory, Weapons and Materials Research Directorate, Aberdeen Proving Ground, MD 21005, USA \\ ${ }^{3}$ Department of Mechanical Engineering, University of California, Riverside, CA 92521, USA \\ ${ }^{4}$ State Key Laboratory for Advanced Metals and Materials, University of Science and Technology Beijing, Beijing 100083, China \\ * Corresponding author. William Yi Wang (Tel.: +1-814-863-9957, e-mail: yuw129@psu.edu)
}

Keywords: Long Periodic Stacking Ordered Structures (LPSOs); Bonding Charge Density; Hardness; Mg alloys.

\begin{abstract}
The present work [1] aims to reveal the effects of solute atoms ( $\mathrm{TM}=\mathrm{Ag}, \mathrm{Zn}$ and $\mathrm{Zr}$ ) on the age-hardening of Mg-Gd-based alloys via the density functional theory and electron work function (EWF) approaches. Based on the electronic structures of LPSOs (including $6 \mathrm{H}, 10 \mathrm{H}, 14 \mathrm{H}, 18 \mathrm{R}$ and 24R) [2], the $10 \mathrm{H}$ LPSO phases of Mg-Gd-TM alloys are selected as the model case due to the improved strength and ductility such long periodic stacking ordered precipitates (LPSOs) offer. The CALPHAD-modeling method is applied to predict the EWF in the ternary Mg-Gd-TM alloys. The obtained EWFs of these Mg alloys match well with previous experimental and theoretical results. Moreover, the variation of EWF in the ternary Mg-Gd-TM alloys is attributed to the structure contribution (i.e., the formation of FCC-type fault layers) and the chemical effect of solute atoms (i.e., electron redistributions characterized by bonding charge density $-\Delta \rho[3-$ 5]). Comparisons of electron redistributions caused by mechanical and chemical contributions of solute atoms posit correlations between EWF and the formation energy of LPSO, which is critical to yield a predictive mesoscale or phenomenological model for age-hardening of $\mathrm{Mg}$. It is found that the interfacial energy of $10 \mathrm{H}$ LPSO is decreased significantly with the addition of $\mathrm{Zn}$ and $\mathrm{Zr}$, indicating the plasticity of $10 \mathrm{H}$ LPSO will be increased in the Mg-Gd-Zr and Mg-Gd-Zn alloys. The enhanced electrons along the basal plane caused by atomic clusters of Gd-TM suggest that the bond strength is improved along basal plane, while the reduced electrons in the prismatic and pyramidal planes indicate the bond strengths are weakened along prismatic and pyramidal planes. The EWF and hardness of Mg$\mathrm{Gd}-\mathrm{TM}(\mathrm{TM}=\mathrm{Ag}, \mathrm{Zn}$ and $\mathrm{Zr}$ ) alloy are also correlated, revealing that the EWF variations of ternary Mg-Gd-TM alloys are attributed to not only the mechanical contribution caused by lattice distortion but also the chemical effect of solute atoms. The attractive combination of physical $(\Delta \rho$ and EWF) and mechanical properties provides a new insight into studying the solid solution hardening behaviors of Mg-RE alloys.
\end{abstract}

\section{References:}

[1] Wang WY, Shang SL, Wang Y, Kim HY, Darling KA, Kecskes LJ, Mathaudhu SN, Hui XD, Liu Z-K. Solid Solution Hardening in Mg-Gd-TM (TM=Ag, Zn and $\mathrm{Zr}$ )
Alloys: An Integrated Density Functional Theory and Electron Work Function Study. JOM 67 (2015) 2433-2441.

[2] Wang WY, Shang SL, Wang Y, Darling KA, Kecskes LJ, Mathaudhu SN, Hui XD, Liu Z-K. Electronic structures of long periodic stacking order structures in $\mathrm{Mg}$ : A firstprinciples study. J. Alloy. Compd. 586 (2014) 656-662.

[3] Nakashima PNH, Smith AE, Etheridge J, Muddle BC. The Bonding Electron Density in Aluminum. Science 331 (2011) 1583-1586.

[4] Wang WY, Shang SL, Wang Y, Darling KA, Mathaudhu SN, Hui XD, Liu ZK. Electron localization morphology of the stacking faults in Mg: A first-principles study. Chem. Phys. Lett. 551 (2012) 121-125.

[5] Wang Y, Wang WY, Chen L-Q, Liu Z-K. Bonding charge density from atomic perturbations. J. Comput. Chem. 36 (2015) 1008-1014.

\section{Graphic abstract}

Electronic and atomic basis for the solid solution hardening in $\mathrm{Mg}$ Alloys

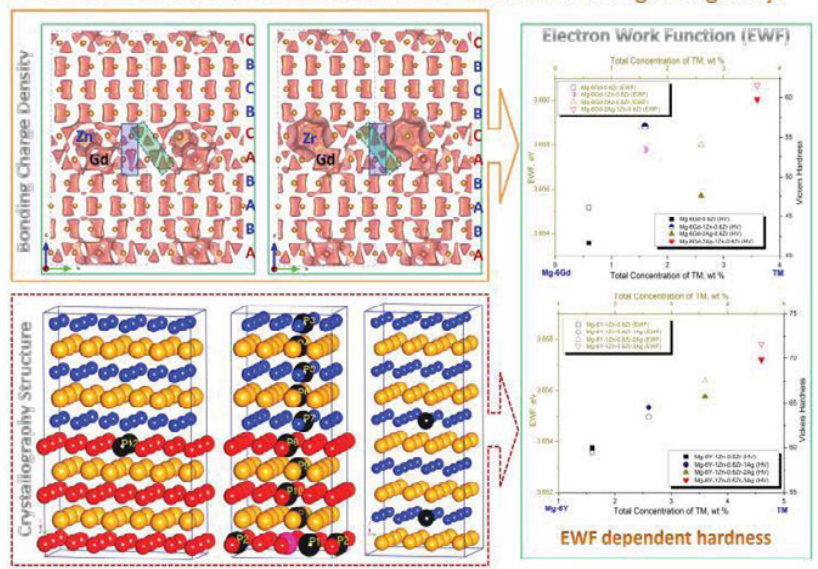

Note: These pictures are reproduced from Ref. [1]. 